\title{
ICT Adoption and the Digital Divide in Serbia: Factors and Policy Implications
}

\author{
Zlatko J. Kovačić \\ The Open Polytechnic of New \\ Zealand, Wellington, \\ New Zealand
}

Zlatko.Kovacic@openpolytechnic.ac.nz

\author{
Dragan Vukmirović \\ Statistical Office of the \\ Republic of Serbia, Belgrade, \\ Serbia
}

\section{Abstract}

This paper explores factors such as socio-demographics, income and wealth and e-skills that may influence the adoption of the ICTs at the individual level. We examine to what extent these factors contribute to the digital divide between different social groups in Serbia.

We use the panel data from the survey "ICT usage in Republic of Serbia" in 2006 and 2007, covering over 3000 individuals/households, to perform a quantitative analysis of the digital divide and ICT adoption. Based on a classification tree and a logistic regression model, a profile of the typical ICT adopter and non-adopter is identified.

The empirical results show the following: (i) the digital divide between age group 55-74 and those younger that 55 slightly increased in 2007 in case of regular Internet use; (ii) at the individual level the ICT adoption (use of PC, Internet and mobile phones) in Serbia is mainly influenced by the income and wealth of an individual, its computer and Internet skills and age; (iii) this result is quite robust across the methodological approaches used; and (iv) the classification tree approach is preferable since it gives the same predictive accuracy as the logistic regression with a more parsimonious model. The policy implications of these results are discussed.

Keywords: ICT adoption, digital divide, Internet usage, gender, education, income, Serbia, classification tree, logistic regression.

\section{Introduction}

\section{The Digital Divide Definition}

In spite of initial optimism that the Internet and ICTs adoption in general would bring the world closer together by redefining time and space, it became evident from the late 1990s that the exist-

Material published as part of this publication, either on-line or in print, is copyrighted by the Informing Science Institute. Permission to make digital or paper copy of part or all of these works for personal or classroom use is granted without fee provided that the copies are not made or distributed for profit or commercial advantage AND that copies 1) bear this notice in full and 2) give the full citation on the first page. It is permissible to abstract these works so long as credit is given. To copy in all other cases or to republish or to post on a server or to redistribute to lists requires specific permission and payment of a fee. Contact Publisher@ InformingScience.org to request redistribution permission. ing social stratification and relations were reproduced in the digital world (Norris, 2001).

The digital divide is a complex phenomenon which has social, political, economical, technological, and educational dimensions. Initially the digital divide was defined as a gap between those who have access to digital ICT and those who do not. Later, the follow- 
ing three interpretations of digital divide were added:

(1) The digital divide is a gap in the ability to use ICTs, measured by PC and Internet skills.

(2) The digital divide is a gap in actual use of ICTs, measured by number of PC users or people online and time they spent using PC or being online.

(3) The digital divide is a gap in the impact of ICTs use, measured by the economic and financial effects ICTs use could bring to an individual, an organization or a country.

The move from the initial digital divide definition toward the last one reflects a change in focus in digital divide research from a technical to a social context. The concept of social inclusion from sociology becoming frequently used in the digital divide research urging for reconceptualization of the digital divide, by broadening it toward models of access for social inclusion (Warschauer, 2002). Similarly, DiMaggio and Hargittai (2001) introduced the term 'digital inequality' which describes not just differences in access (labeled as the first-level, or basic digital divide), but autonomy of use, skill, social support and the purposes for which the technology is employed (labeled as the second-level digital divide). Such a shift in the digital divide research focus requires an equivalent shift in the digital divide measurement as argued by Barzilai-Nahon (2006). She went even further suggesting that the network and associate technologies are not neutral artifacts but are political and social spaces in their structure as well as in their content levels. She pleaded for the use of so-called comprehensive rather than the monotopical indices that were predominant in the previous research. Similarly, Vehovar, Sicherl, Hüsing and Dolničar (2006) argued that some digital divide indicators could take different or even contradictory values. Therefore they proposed a more wider and complex approach to the digital divide measurement using so-called compound measure, multivariate modeling and time-distance methodology.

The digital divide and the ICTs adoption were studied at three different levels: micro (individuals and households), mezzo (organizations) and macro level (regions and countries). In this paper both phenomena are analyzed at the micro level. The most comprehensive and up-to-date overview of digital divide research is given in Dewan and Riggins (2005).

\section{E-readiness in Serbia - Prospect and Obstacles}

To get a better understanding of the results at the micro level we briefly discuss a few basic ICT adoption indicators at the national level for Serbia and neighboring countries of the Western Balkan. Knežević and Vidas-Bubanja (2006) gave an overview of the Serbian e-readiness, while Baćević (2003) provided the development of the Internet in Yugoslavia.

According to the United Nations (2005) e-government readiness benchmark survey, Serbia, together with other Western Balkan (South East European) countries such as Albania, Bosnia and Herzegovina, and Montenegro is ranked below most other European countries. On a worldwide scale, Serbia is improving its position, moving slowly from $89^{\text {th }}$ position in 2003 to $87^{\text {th }}$ in 2004 and finally to $78^{\text {th }}$ position in 2005 . The last figure is our calculation, since the UN (2005) report has incomplete data for Serbia.

The basic indicators of ICT adoption in selected Western Balkan countries in 2005 are presented in Table 1.

There are great variations between these countries in the number of PCs, Internet users and the online population. However, only Slovenia, who recently joined the European Union (EU), has values for these indicators comparable to values in other countries, that are members of the EU. Serbia and Montenegro (both are now independent countries), Bosnia and Herzegovina, Macedonia and Albania are well behind the rest of Europe in all indicators of ICT adoption. Of course, for a coherent plan of action to address the digital divide components beside these highly aggre- 
gated synthetic e-readiness indicators, for each country a unique profile how ICT is accessed and used is required. This profile should capture the multidimensional nature of the digital divide phenomenon.

Table 1: ICT adoption in selected Western Balkan countries in 2005 (per 100 persons)

\begin{tabular}{lcccc}
\hline \multicolumn{1}{c}{ Country } & PC & Internet users & Online population & Mobile subscribers \\
\hline Slovenia & 32.50 & 40.10 & 31.13 & 87.09 \\
Croatia & 17.40 & 23.20 & 11.07 & 58.37 \\
Macedonia & - & 4.85 & 4.90 & 17.70 \\
Serbia \& Montenegro & 2.70 & 7.90 & 2.81 & 33.78 \\
Bosnia \& Herzegovina & - & 2.60 & 1.14 & 27.40 \\
Albania & 1.20 & 1.00 & 0.34 & 35.80 \\
\hline
\end{tabular}

Source: UN(2005).

While the Serbian economy in transition is facing the same problems common to other Eastern European economies in transition, there are also a few additional restrictions and obstacles specific to this country in its attempt to improve its position on the e-readiness list. In the following two paragraphs we discuss briefly some of these obstacles.

The international sanction imposed on Yugoslavia reduced communication with the outside world to a minimum. While the sanctions did not hit the regime significantly, they heavily targeted its population, economy and consequently the development and adoption of ICTs. At the same time the regime put all its efforts and resources into stopping those who were using new ICTs, Internet in particular, to inform Serbian society (Stojković, 2003). The peak of the regime's activities was during the war in 1999 when already poor and outdated telecommunications infrastructure were further destroyed/devastated during NATO bombardment. According to European Bank for Reconstruction and Development (as cited in Horvitz, 2002) Telekom Srbija put the combined cost of "restoring and modernizing all the damaged telecom facilities (including Kosovo) at almost US\$ 2 billion." The direct costs are probably much lower due to the fact that outdated network facilities would be replaced anyway, even without bombing. However, this figure signifies the fact that there is an urgent need for massive capital investment in telecommunication infrastructure in Serbia.

The slow increase in Internet use in Serbia could be partly attributed to the late start of transition and delayed privatization of the telecommunication companies. Guillén and Suárez (2005) confirmed the hypothesis that privatization of the incumbent telecommunication provider indeed increases Internet use. They also have shown that competition in local phone service increases Internet use. With the strong monopoly of the state owned telecommunication companies and a few Internet service providers (Horvitz, 2002) it is not surprising that Serbia has one of the highest prices for Internet connection in the region. According to Guillén and Suárez (2005) competition in local phone service increases Internet use. Bauer, Berne and Maitland (2002) have also shown, for the most advanced countries, that competition has an effect on Internet use, controlling the cost of access. However, when Internet penetration is concerned Kiiski and Pohjola (2002) found for the OECD countries that the deregulation of the telecommunication sector improves Internet connectivity only if it lowers the access cost. Due to very restrictive conditions and high barriers for entry into the telecommunication market for foreign companies it is highly unlikely to expect the further price reduction that would otherwise occur due to the competition in the telecommunications section. These are some of the obstacles and factors that might influence the speed of the ICT adoption in Serbia at all three levels. Knežević and Vidas-Bubanja (2006) also discussed the technical restrictions for further expansion of e-business in Serbia pointing to 
the inadequate telecommunication infrastructure and low Internet penetration. Among nontechnical factors limiting further adoption of e-business in Serbia the following factors were listed: low income per capita, absence of a legal framework in the telecommunication sector, a monopoly in the fixed phone services, the high cost of access, a lack of vision and strategy for ecommerce by the Serbian Government, and a lack of knowledge what opportunities an introduction of e-business could bring to the organizations and the national economy.

\section{Research Questions}

The main objective of this study is to explore ICT adoption and explain the digital divide in Serbia. These issues have not been examined so far for Serbia and the paper attempts to fill the gap. More specifically the survey data were used to address the following questions:

- Is there a digital divide in Serbia?

- If the gap exists, what are the main determinants of the digital divide?

- Which method used to separate ICTs adopters from non-adopters outperforms other methods in term of classification accuracy?

Before answering these questions a brief overview of the previous empirical studies of the ICTs adoption and digital divide is given, focusing on the micro level. Based on the literature review a conceptual model for ICT adoption was built and discussed together with the hypotheses. The methodology and data section describes the survey instrument, data as well as the statistical methods and models used in this study. Empirical results are presented in the section that follows. The final section discusses the implications of these results.

\section{Literature Review}

The digital divide and the ICTs adoption were studied at three different levels:

- Macro level (regions and countries)

- Mezzo level (organizations)

- Micro level (individuals and households)

In this paper both phenomena are analyzed at the micro level. However, to get an overall picture of ICT adoption and the digital divide the following three subsections give a brief overview of the factors, issues and results related to these phenomena at all three levels.

\section{ICT Adoption and Digital Divide at Macro Level}

Different aspects of ICT adoption and diffusion as well as the digital divide at the macro level were investigated in numerous research papers. In this section a brief overview of the results and factors considered is presented. When examining the differences in ICT adoption and digital divide worldwide, the number of Internet hosts, PC and mobile subscribers were the most frequently used dependent variables.

The following list gives the main factors, i.e. independent variables as well as the selection of empirical studies analyzing ICT adoption models and digital divide at the macro level:

(1) National income. It was identified as one of the most influential factors (BaliamouneLutz, 2003; Chinn \& Fairlie, 2004; Dewan, Ganley \& Kraemer, 2005; Guillén \& Suárez, 2005; Kauffman \& Techatassanasoontorn, 2005; Kiiski \& Pohjola, 2002). Guillén and Suárez (2005) found that the differences in Internet use across countries are fundamentally related to economic variables such as per capita income and the cost of access. 
However, as Baliamoune-Lutz (2003) pointed out, it is not quite clear what the nature of relationship in between ICT adoption and economic growth and what the direction of causality is between them. Beilock and Dimitrova (2003) discovered that per capita income was the most important determinant of the inter-country differences in Internet usage rates. The relationship appears to be non-linear with greater impact at the lower level. Dewan, Ganley, and Kraemer (2005) found that IT penetration is positively associated with national income and the association is stronger for countries with higher levels of IT penetration.

(2) Access cost. The low service prices are likely to increase ICT adoption (Guillén \& Suárez, 2005; Kauffman \& Techatassanasoontorn, 2005; Kiiski \& Pohjola, 2002).

(3) Trade policy. Baliamoune-Lutz (2003) found that the government trade policy and country's openness have a positive impact. (See also Beilock \& Dimitrova, 2003; Guillén \& Suárez, 2005.)

(4) Competition in the telecommunication sector. Hargittai (1999), Kiiski and Pohjola (2002) and Guillén and Suárez (2005) considered this factor. However, the results were contradictory. Hargittai (1999) found that it is negatively related to the Internet connectivity, while Kiiski and Pohjola (2002) found they were not significantly related. Kauffman and Techatassanasoontorn (2005) suggested that competition on the telecommunication market is likely to increase the rate of growth of digital wireless phone subscribers.

(5) ICT infrastructure. Infrastructure indicators were identified as statistically significant factors contributing to variation in PC and Internet penetration (Beilock \& Dimitrova, 2003; Chinn \& Fairlie, 2004; Dimitrova, 2002; Kiiski \& Pohjola, 2002) and are likely to increase the rate of growth of digital wireless phone subscribers (Kauffman \& Techatassanasoontorn, 2005)

(6) Spillover. The geographical influence on ICT adoption should be taken into account, i.e. the contagion effect that likely exists between neighboring countries or countries belonging to the same region. Crenshaw and Robinson (2006) have shown that both similarity between developing and developed countries (economic, social and political structure) and contact with developed countries are important for Internet development within developing countries. Kauffman and Techatassanasoontorn (2005) detected the spillover effect, which means that a country's diffusion is also influenced by the diffusion process in other countries within the same region.

(7) Democracy. Dimitrova (2002) contrary to Guillén and Suárez (2005) findings is suggesting that in the case of post-communist countries, democratization (civil liberties) has a significant and even stronger impact on the Internet adoption than national income and telephone infrastructure. In the case of Internet hosts and mobile phones political rights and civil liberties have a strong association (Baliamoune-Lutz, 2003). See also: Norris (2001).

(8) Other factors. Among other factors affecting Internet adoption or diffusion the following were suggested: national culture (van Everdingen \& Waarts, 2003), English language (Kiiski \& Pohjola, 2002), income distribution (Hargittai, 1999), government trade policy (Baliamoune-Lutz, 2003), privatization and deregulation of the telecommunication sector (Guillén \& Suárez, 2005; Kiiski \&\& Pohjola, 2002), technical standards (Kauffman \& Techatassanasoontorn, 2005), technological policy (Kiiski \& Pohjola, 2002), country's regime type (Milner, 2006), education (Baliamoune-Lutz, 2003) and cosmopolitanism (Guillén \& Suárez, 2005). 
Most of the empirical studies referenced so far were based on worldwide data. However, some authors considered regional data only focusing on the specific issues relevant to a particular region, or group of countries. The following list gives a brief overview of their results:

(1) $\boldsymbol{O E C D}$. Kiiski and Pohjola (2002) analyzed the factors that may influence the diffusion of the Internet in OECD and across the world by using the Gomperz model of technology diffusion. For OECD countries income and price, i.e. GDP per capita and Internet access cost explained most of the observed Internet penetration measured with computer hosts per capita. There were also some indications that there are the cultural or technology policy related differences between OECD countries.

(2) EU countries. Similarly to Vehovar, Sicherl, Hüsing and Dolničar (2006) Cuervo and Menéndez (2006) also used multivariate statistical methods of factor and cluster analysis to analyze the digital divide between European Union countries. Two significant factors emerged: the first related to ICT infrastructure and use and the second related to cost and availability of online public services.

(3) Asian countries. Wong (2002) examined ICT adoption among Asian countries. Despite their high contribution to a global production of ICT goods most of them are laggards in the adoption of IT. Moreover, the digital divide, particularly in the Internet-related areas, is higher among Asian than among non-Asian countries after controlling for their level of economic development or competitiveness.

(4) Sub-Saharan Africa. Oyelaran-Oyeyinka and Lal (2005) found that the diffusion of the Internet is significantly influenced by the density of Internet hosts and personal computers and also indirectly with economic wealth and telephone density. The number of Internet hosts is influenced by telecommunication infrastructure investments from the previous year and existing telephone density.

Dewan and Riggins (2005) summarized the digital divide research at the global level considering topics such as ICT penetration, Internet penetration and the digital wireless penetration.

\section{ICT Adoption and Digital Divide at Mezzo Level}

Though we are discussing factors that might have an impact on ICT adoption at three different levels a research framework that encompasses variables from all three levels could be built as Waarts and van Everdingen (2005) demonstrated. The primary goal of their research was to investigate the role of a macro variable such as national culture in providing an explanation of the differences in adoption of enterprise resource planning systems by mid size companies. Their results confirm strong and significant influence of national culture on innovation penetration and adoption at the organizational level. They have also provided an extensive overview of the literature on the adoption at the mezzo level, with detailed discussion of the factors at the micro, mezzo and macro levels that might influence the innovation penetration at the organizational level. Briefly, at the micro level two categories of variables were identified: perceptions of the innovation characteristics and the adopter characteristics. While at the mezzo level the two types of factors might influence ICT adoption at the organizational level: industry competitiveness and supply side activities targeted at the industry such as marketing activities of suppliers. See also: van Everdingen and Waarts (2003).

Dinlersoz and Hernández-Murillo (2004) documented the extent of the diffusion in three main sectors of the economy: retail, services, and manufacturing in the U.S. economy. They found that the travel industry leads the services sector in terms of adopting e-business and technologically advanced manufacturing industries tend to rank high in the adoption of Internet-based processes used to facilitate production. They also found a positive and statistically significant relationship 
between adoption rates and a firms' plant size. Firm size was also identified as a significant factor in e-commerce adoption by agribusiness firms in U.S. (Henderson, Dooley, \& Akridge, 2000) and banks in Western Europe (Bughin, 2001). Location was another significant factor in Internet adoption identified by Forman, Goldfarb \& Greenstein (2005). Bughin (2001) dealt with the socalled push and pull factors that may influence the online customer penetration in Western Europe banks. He found that the customer conversion to Internet banking depends on pull factors such as some key consumer demographics (for example, education) and consumer readiness to transact online. Among push factors the following were identified: bank size, lower cost structure, and adoption of a global cost-effectiveness strategy. Pull factors were contributing about twothird of the variation to the customer conversion to Internet banking, while push factors contributed only one-third.

Köllinger and Schade (2003) analyzed factors that may influence the adoption of e-learning in almost 6,000 firms in 15 industry sectors. They found an increasing digital divide in respect to elearning adoption among firms influenced by existence of technological interdependencies and organizational learning effects. Finally, Dewan and Riggins (2005) summarized the digital divide research at the organizational level considering topics such as role of firm size and promotion by top management.

\section{ICT Adoption and Digital Divide at Micro Level}

The following list gives the main factors, i.e. independent variables as well as a selection of empirical studies analyzing ICT adoption and the digital divide at the micro level:

(1) Socio-demographics. This is the most frequently considered group of factors in empirical research at the micro level. It includes: gender, age, family/household size, family/household structure, housing type, education level, and employment status. Initially significant differences were identified between genders in relation to the ICT adoption. However, as the Pew Internet Project (2005) reports, this gap in the ICT adoption between genders diminished. It would be expected that the proportion of women online is nearly equal to that of men. However, the digital divide between genders measured by the amount of time spent online should not be the only focus of digital divide research. Kennedy, Wellman and Klement (2003) argued that it is more important to gain understanding why there are differences between women and men when using the Internet. As far as age is concerned, the number of senior citizens online is increasing, but they are still behind the younger generation (Pew Internet Project, 2004, 2006). McLaren and Zappalà (2002) found that for the children in Australia from financially disadvantaged backgrounds the level of parental education was most strongly associated with home access to computer and Internet as well as computer and Internet usage. Harrington (2003) reported that the major components of the digital divide are narrowing in the People Republic of China (gender, age, education group seem to diminishing over time). Tukiainen (2004) investigated factors that affect individual access to ICT (computer, Internet and mobile phone) in selected European countries. He found that adoption of a new technology is affected by household type and age. Choudrie and Dwivedi (2006) examined the socioeconomic determinants of broadband adopters and non-adopters of broadband in the UK households. They found that age, gender, education level and social grade have a significant impact on adoption.

(2) Economic factors. This factor includes: income and wealth. Tukiainen (2004) found that income is also one of significant factors affecting ICT adoption in Finland, Ireland, Netherland and Sweden. Choudrie and Dwivedi (2006) found that beside the standard set of demographic variables, income has a significant impact on broadband adoption in UK households. Among factors that influence the working population in Malaysia to use ICT 
Tengku (2005) identified: nature of job and income. See also: Curry \& Kenney (2006) and Eamon (2004).

(3) ICT infrastructure. This factor is concerned with the availability of ICT infrastructure that may restrict an individual from regular use of ICTs. Curry and Kenney (2006) argued that for Mexico the digital divide is predominantly an economic and historic phenomenon rather than driven primarily by technology. See also: Ferro, Cantamessa \& Paolucci (2005)

(4) Geographical factors. Living in an urban or rural area, or in city centers may have a significant impact on ICT adoption and use. Harrington (2003) reported that inter-provincial differentials are narrowing in the People Republic of China. Tengku (2005) examined the digital divide between urban and rural populations in Malaysia. He found that while for the urban population income is not a significant factor, it is significant for the rural population. However, some precautions should be taken when addressing the digital divide between rural and urban populations. For example, Ferro, Cantamessa, and Paolucci (2005) studied the digital divide between urban and rural areas in Italy. Their results show that investing in physical infrastructures to connect rural areas will only partially address the issue of digital divide, since it would simply shift the problem from a geographical to a socio-economic sphere. See also: McLaren \& Zappalà (2002), Tukiainen (2004).

(5) Culture and ethnicity. Hoffman and Novak (1998) and Novak, Hoffman, and Venkatesh (1998) analyzed the racial divide on the Internet while McLaren and Zappalà (2002) were focused on the children in Australia from financially disadvantaged backgrounds. They found that ethnic and cultural backgrounds are also associated with home access.

(6) $\boldsymbol{E}$-skills. Tengku (2005) examining the digital divide in Malaysia identified the latent variable 'tutorial available to study ICT' as significant in explaining the variation in the Internet usage among senior high students. As Hargittai (2002) suggested, policy measures that aim to bridge the gap in the access and use of ICT should also consider investment in training and support. Giving access to the Internet connected PC will not ensure that the users with a lack of PC and Internet skills will be able to use ICT beneficially.

Dewan and Riggins (2005) provided a summary of digital divide research at the individual level, considering topics such as ICT adoption, efforts to bridge the divide and patterns of ICT usage.

\section{Research Framework}

\section{Conceptual Model}

Based on the discussion of factors that may influence ICT adoption and the digital divide we are proposing the following conceptual model (Figure 1) for investigating ICT adoption in Serbia at the micro level.

ICT adoption encompasses the use of different technologies. Therefore when analyzing ICT adoption we are focusing on the use of the main ICT, namely PCs, the Internet and mobile phones. To understand what separates ICT adopters from non-adopters we are examining the factors that are likely to play an important role in separation. These factors were grouped into the three main groups of factors which we labeled as socio-demographics, income and wealth and eskills. According to the conceptual model regular use of a PC, regular access to the Internet and use of a mobile phone are the dependent variables related to an individual who adopted a particular technology. 
The income and wealth block of factors includes the monthly income of an individual and the wealth of an individual measured indirectly through possession of a PC and access to the Internet at home. The rationale for using the last two indicators as a measure of wealth is the following. Due to the high prices and taxation of PCs and equipment (a few average monthly salaries for a standard system) the PC in Serbia is still considered as a luxury good and a status symbol. The same is with access to the Internet from home. Beside the initial investment of establishing a connection to the Internet provider, there are ongoing monthly subscription costs of up to almost $10 \%$ of the monthly average salary. These regular expenses related to the Internet subscription are simply not affordable for most families in Serbia. It is also worth mentioning that owning a PC and having access to the Internet from home is more convenient for PC and Internet users than to visit cyber cafes, though they are available around the country.

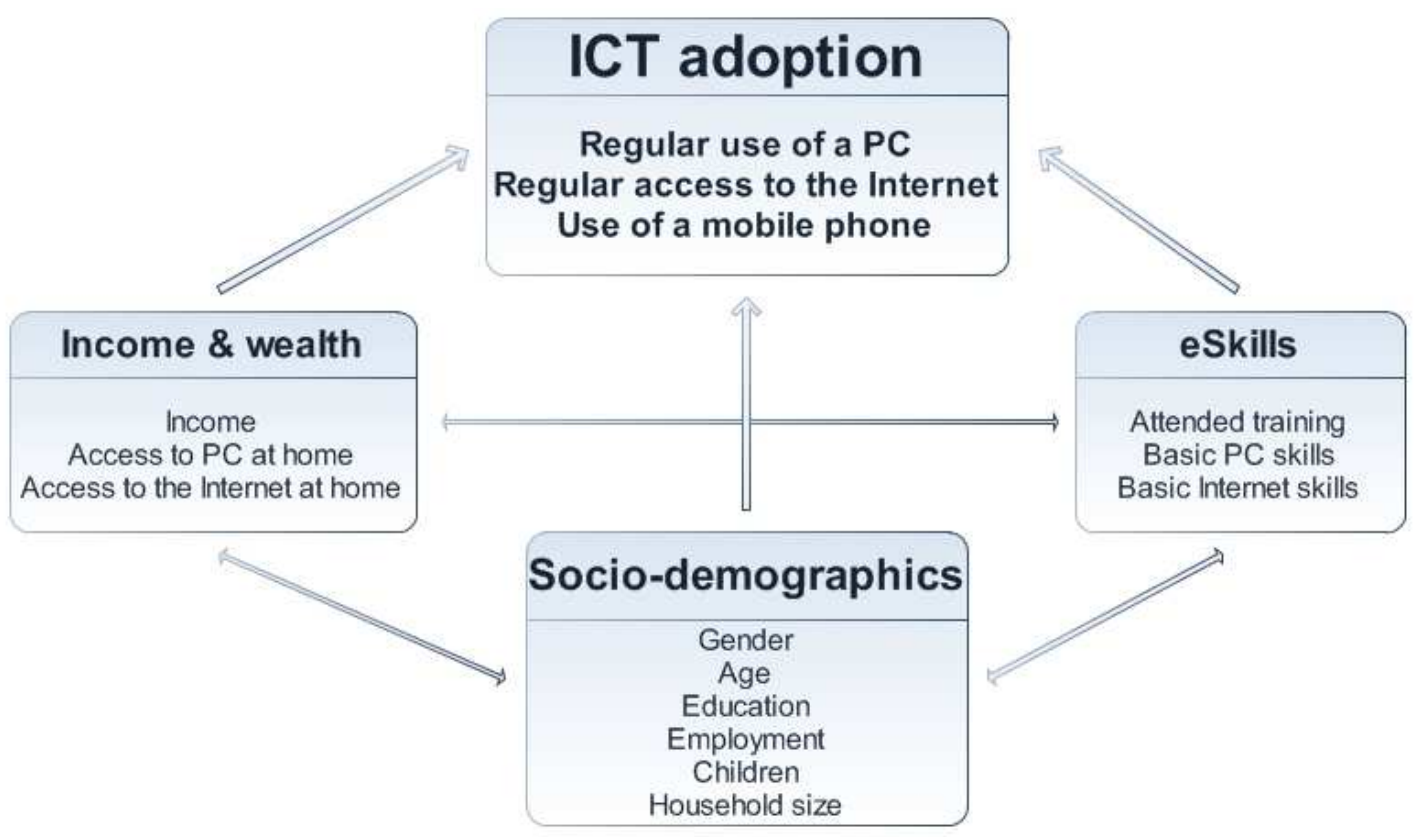

Figure 1: ICT adoption in Serbia - conceptual model

The socio-demographics block consists of standard indicators used in the similar studies. Namely, gender, age, education, and employment status of an individual and whether there are children in the household or not and the size of the household.

The last block, labeled e-skills, contains factors related to the proficiency of an individual with basic PC operations such as copying, moving and pasting and basic Internet skills (emailing and browsing). We added also to this block a related indicator, i.e. training on using computers or a lack of it.

\section{Hypotheses}

Based on the literature review and the conceptual model in Figure 1 the following research hypotheses are formulated:

Hypothesis H1: There is a significant difference in ICT adoption as a result of sociodemographic characteristics of the Serbian population

According to the results of the digital divide research at micro level summarized before, we would expect that 
- Gender has no significant impact on ICT adoption

- ICT adoption decreases with age

- ICT adoption increases with the education level

- Employment status has a significant positive impact on ICT adoption

- Household structure (size and children in household) has a significant impact on ICT adoption

Hypothesis H2: There is a significant difference in ICT adoption based on differences of income and wealth of the Serbian population.

In developing countries the first order digital divide, i.e. who has access to technology is one of main obstacles for ICT adoption. We would expect that regular use of ICT in Serbia is significantly affected by the level of income and wealth. Affordability is still the key word on which the policy-makers who want to close the digital gap should focus. Higher income is expected to positively affect ICT adoption. In other words, we would expect an increase in number of ICT adopters in the segment of the Serbian population which earns a high-income.

Hypothesis H3: There is a significant difference in ICT adoption based on differences of eskills of the Serbian population.

Though PCs, the Internet and mobile phones are becoming more and more "user-friendly", i.e. easier to use, there are still a certain set of e-skills required for confident use of technology. Those who lack basic e-skills would hesitate to use a technology even if they have access to it at home. In general, more technology savvy users are expected to adopt a new technology at its early development stage and benefit more from using it, than those who lack basic e-skills.

\section{Data and Methodology}

Any empirical research faces many obstacles. Finding strong research evidence of Internet adoption, actual use and the digital divide in Serbia and other Western Balkan countries is a real methodological challenge in many respects as Kostov (2006) noticed.

Before the year 2006, several different but mostly partial data about ICT usage in the Republic of Serbia were gathered. The data were obtained using different survey instruments and based on different methodologies that are not harmonized with methodologies of similar surveys conducted in the EU countries. The lack of consistent ICT usage data for the whole country triggered the Statistical Office of the Republic of Serbia to introduce two surveys on ICT usage (hereafter: survey) in its program of regular surveys, commencing from 2006. The first covers households/individuals, while the other collects data about ICT usage among enterprises. Surveys for 2006 and 2007 were conducted according to the EUROSTAT methodology. The results are comparable with the results from all EU countries conducting the same survey. Unified methodology and the same survey instrument allow international comparison and help identify the position Serbia has among other EU countries with regard to ICT usage.

\section{Survey}

To enhance the comparability across countries, EUROSTAT provides a model questionnaire. EUROSTAT designed the model questionnaire in close cooperation with the national statistical institutes, the main users and in coordination with other organizations such as the OECD. All questions from the EUROSTAT's model questionnaire were included in the Serbian questionnaire. A few questions have been added because of the special interest for such data in Serbia (for 
example: devices represented in households). Before the interviewing process the questionnaire was pre-tested on 20 randomly selected households.

A telephone interview was used. If the household members were not at home during the first call they were called later. Proxy interviews were allowed. The survey was conducted by 40 interviewers who had completed training on how to conduct a telephone interview.

The questions in the survey generated nominal variables which allow for only qualitative classification, i.e. the aim was not to collect information on quantities ("how many ..."), frequencies ("how often ...") or amounts ("how much ...") but rather to obtain non-numerical or categorical information. For most questions the binary (dichotomous) variables were generated, which means the respondent answered these questions with "yes" or "no" (e.g. Have you used the Internet for selling goods or services?) Other variables generated were also nominal variables, but with more than two categories, for example: highest educational level.

\section{Sample}

Depending on the particular question the following statistical units were used:

- Households

- Individuals

The target population is the population of interest. In the survey, the target populations for the two statistical units were:

- Individuals: target population consisted of all individuals aged 16 to 74;

- Households: target population consisted of all households with at least one member aged 16 to 74 .

The last survey was carried out from 24 April to 10 May 2007. The reference period for the ICT use related variables depends on the particular question. It could be, for example the first quarter of the year, or the January 2007. The whole territory of the country was included, apart from Kosovo and Metohija. The sampling frame is based on the data from the Population Census conducted in 2002 which includes household living in Serbia. Gross sample size was 2000 households/individuals. Total response rate was $96.9 \%$.

The sample was based on a two-stage stratified random sampling design. Primary sampling units were enumeration districts and second stage units were households. The stratification of enumeration districts was done according to the type of settlement (urban and rural) and administrative region (14 administrative regions). Enumeration districts were stratified proportionally to the number of households by regions as well as urban and rural areas. Enumeration districts were selected with probabilities proportional to the number of households, and from each enumeration district 5 households were randomly selected. Target persons (persons aged between 16 and 74 years) were selected from the household which was chosen.

Two questions in the survey were used to draw a line between ICT adopters and non-adopters. Those participants who answered "Within the last 3 months" the question: "When did you last use the computer/Internet?" and "Every day, or almost every day" the question: "How often, on average, did you use the computer/Internet within the last 3 months?" were labeled "PC/Internet Adopters", all the others were labeled "Non-adopters". Mobile phone users were identified as those participants who positively answered the survey question: "Do you use a cellular telephone?"

A detailed description of variables is given in Table 2. 


\section{Methodology}

The simple summary statistics such as the differences between percentages of a particular group and the reference group is used to illustrate the size of the digital divide in Serbia. To classify an individual as an adopter or non-adopter of ICT two methods were used: non-parametric approach of the classification tree (Gatnar, 2002) also known as recursive partitioning and logistic regression (Agresti, 2002). The logistic regression was also used to test the set of hypotheses formulated above.

Table 2: Description of variables and their reference groups

\begin{tabular}{|c|c|}
\hline Variable & Variable description \\
\hline Year & $=1$, for data in 2007, and $=0$ for data in 2006 \\
\hline Gender & $\begin{array}{l}=1 \text {, for male participant, and }=0 \text { for female participant (reference } \\
\text { group). }\end{array}$ \\
\hline Gender * Year & $\begin{array}{l}\text { Capture the effect of changing impact that gender might have on the } \\
\text { ICT adoption in } 2006 \text { and } 2007 .\end{array}$ \\
\hline Age & $\begin{array}{l}=1 \text {, for } 16-24 \text { old participant }=2 \text {, for } 26-54 \text { and }=3 \text {, for } 54-74 \text { (refer- } \\
\text { ence group). }\end{array}$ \\
\hline Age * Year & $\begin{array}{l}\text { Capture the effect of changing impact that age might have on ICT } \\
\text { adoption in } 2006 \text { and } 2007 .\end{array}$ \\
\hline Education & $\begin{array}{l}=1 \text {, participant has less than high school (reference group) } ;=2 \text {, high } \\
\text { school and }=3 \text {, higher education than high school. }\end{array}$ \\
\hline Employment & $\begin{array}{l}=1 \text {, participant is employed } ;=2, \text { unemployed } ;=3 \text {, student and }=4 \text {, } \\
\text { other (reference group) }\end{array}$ \\
\hline Children & $\begin{array}{l}=1, \text { if there is at least one child in the household, }=0 \text {, no children in } \\
\text { the household (reference group). }\end{array}$ \\
\hline Household size & Number of household members. \\
\hline Income & $\begin{array}{l}=1 \text {, participant's monthly income is less that } 300 \text { euros (reference } \\
\text { group); }=2 \text {, between } 300 \text { and } 600 \text { euros and }=3 \text {, over } 600 \text { euros. }\end{array}$ \\
\hline Income $*$ Year & $\begin{array}{l}\text { Capture the effect of changing impact that income might have on ICT } \\
\text { adoption in } 2006 \text { and } 2007 .\end{array}$ \\
\hline Access to a PC at home & $\begin{array}{l}=1, \text { anyone in the household has access to a PC, laptop or palmtop at } \\
\text { home },=0 \text {, otherwise (reference group). }\end{array}$ \\
\hline Access to the Internet from home & $\begin{array}{l}=1 \text {, anyone in the household has access to the Internet from home, }=0 \text {, } \\
\text { otherwise (reference group). }\end{array}$ \\
\hline Training taken & $=1$, participant attended a training; $=0$, otherwise (reference group) \\
\hline Basic PC skills & $\begin{array}{l}=1, \text { participant copied and moved files and folders and used copy and } \\
\text { paste tools; }=0, \text { otherwise (reference group). }\end{array}$ \\
\hline Basic Internet skills & $\begin{array}{l}=1 \text {, participant used a browser in a quest for information and sent e- } \\
\text { mails with attachments }=0 \text {, otherwise (reference group). }\end{array}$ \\
\hline Use of a PC & $\begin{array}{l}=1 \text {, participant used a computer in the last } 3 \text { months; }=0 \text {, otherwise } \\
\text { (reference group). }\end{array}$ \\
\hline Regular use of a PC & $\begin{array}{l}=1, \text { participant used a computer every day, or almost every day, or at } \\
\text { least once a week; }=0 \text {, otherwise (reference group). }\end{array}$ \\
\hline Use of the Internet & $\begin{array}{l}=1 \text {, participant accessed the Internet in the last } 3 \text { months; }=0 \text {, other- } \\
\text { wise (reference group). }\end{array}$ \\
\hline Regular use of the Internet & $\begin{array}{l}=1, \text { participant used the Internet every day, or almost every day, or at } \\
\text { least once a week, }=0 \text {, otherwise (reference group). }\end{array}$ \\
\hline Use of mobile phone & $=1$, participant used a mobile phone, $=0$, otherwise (reference group) \\
\hline
\end{tabular}




\section{Results}

Before growing the classification tree and estimating the logistic regression for each of the technologies (PC, Internet and mobile phones) we summarized a set of selected variables by key socio-economic dimensions to illustrate the scope of the various digital divide aspects in Serbia.

\section{Summary Statistics}

Table 3 reports various digital gaps as the differences between the percentage for a particular group and the percentage of the reference group. The reference groups are: female in case of Gender, age group 55-74 in case of Age and "less than €300" income group in case of Income.

Table 3: Access, ability to use and actual use of ICT gaps by gender, age and income (\%)

\begin{tabular}{lccccc}
\hline \multirow{2}{*}{ Variable } & \multirow{2}{*}{ Gender } & \multicolumn{2}{c}{ Age } & \multicolumn{2}{c}{ Income } \\
\cline { 3 - 6 } & & $16-24$ & $25-54$ & $€ 300-600$ & $>€ 600$ \\
\hline Have access to a PC at home & 6.1 & 51.6 & 36.2 & 35.9 & 54.0 \\
Have access to the Internet at home & 5.5 & 43.9 & 27.2 & 33.9 & 53.4 \\
Have basic PC skills & 7.5 & 69.9 & 40.1 & 40.1 & 53.7 \\
Have basic Internet skills & 7.5 & 65.0 & 38.5 & 42.2 & 58.5 \\
Regular use of a PC & 7.5 & 67.2 & 41.2 & 41.5 & 57.8 \\
Regular access to the Internet & 9.1 & 51.9 & 32.8 & 37.3 & 54.2 \\
Use of a mobile phone & 6.5 & 50.6 & 41.8 & 28.0 & 33.6 \\
\hline
\end{tabular}

The gender divide increases when basic PC and Internet skills are considered. The largest gender gap is in the case of regular access to the Internet. The gender gap is comparable with the data for the European Union (Angela \& Sicat, 2004). However, the surveys in Serbia were undertaken 4-5 years later than in European Union countries which indicates also the possible lag between Serbia and European Union.

Significantly larger gaps are discovered when we consider the age and income of participants. The reference age group 55-74 in particular is dramatically left behind. The difference between them and the younger generation (age group 16-24) is almost 70\%. Even in the case when they have access to PC at home they lack the basic PC skills to become a regular PC user. They may also lack of information on how a computer could be used at home or at work to increase productivity. In both cases the education of the most senior citizens might close the gap between them and the rest of the society. The gap is slightly smaller in the case of regular access to the Internet, but still over $50 \%$.

Finally, the income is still the important variable, which discriminates those who are ICT adopters from those who are not. The largest gap is identified between regular PC users and nonregular users; this is slightly smaller in the case of regular Internet users. The age and income digital divide increase when basic PC and Internet skills are considered. The smallest gap, but still significant is detected for mobile phone users. The difference between mobile phone users in the highest income group (over €600) and lowest income group (less than €300) is about $33 \%$.

\section{Classification Tree}

The objective of an analysis based on a classification tree is to identify factors that contribute the most to the prediction of whether the participant is an ICT adopter or not. When the classification tree is formed we can calculate the probability of each participant being an ICT adopter. In the following three figures (Figure 2 to 4 ) the classification trees for the regular PC, Internet and mobile phone users are given. In each tree node the number of ICT adopters $\left(2^{\text {nd }}\right.$ line left $)$ and non- 
adopters ( $2^{\text {nd }}$ line right $)$ is given, as well as the ratio of adopters ( $3^{\text {rd }}$ line left $)$ and relative size of the node $\left(3^{\text {rd }}\right.$ line right $)$. The node has an oval shape, while the terminal node is rectangular. The variable names below the nodes are the predictors that provided the best split for the node according to the classification and regression tree-style exhaustive search for univariate splits method. This method looks at all possible splits for each predictor variable at each node. The search stops when the split with the largest improvement in goodness of fit, based on the Gini measure of node impurity, is found. Note that all available variables in the dataset were included in the classification tree analysis excluding three interaction variables (gender, age and income).

\section{PC adopters}

The classification tree for the regular use of a PC is presented in Figure 2. It shows that only 6 variables were used to construct the tree: (1) basic PC skills, (2) access to a PC, (3) basic Internet skills (4) employment status (5) training and (6) age. The largest non-adopter group (i.e. not regular PC users) consists of 1498 (48.7\%) participants in the survey (Node 4). This group has the following in common: they don't have basic PC skills and don't have access to a PC at home. The largest adopter group (i.e. regular PC users) contains 984 participants (32\% of all participants) (Node 7). They have basic PC skills and access to PC at home. The next largest group considered also as adopters, contains 187 , i.e. $6.1 \%$ of all participants, where $68.5 \%$ of them are adopters (Node 10). They have basic PC skills, but don't have access to a PC at home and they are either employed or students. In other words they are probably using a PC on a regular basis but only at work or at school/university.

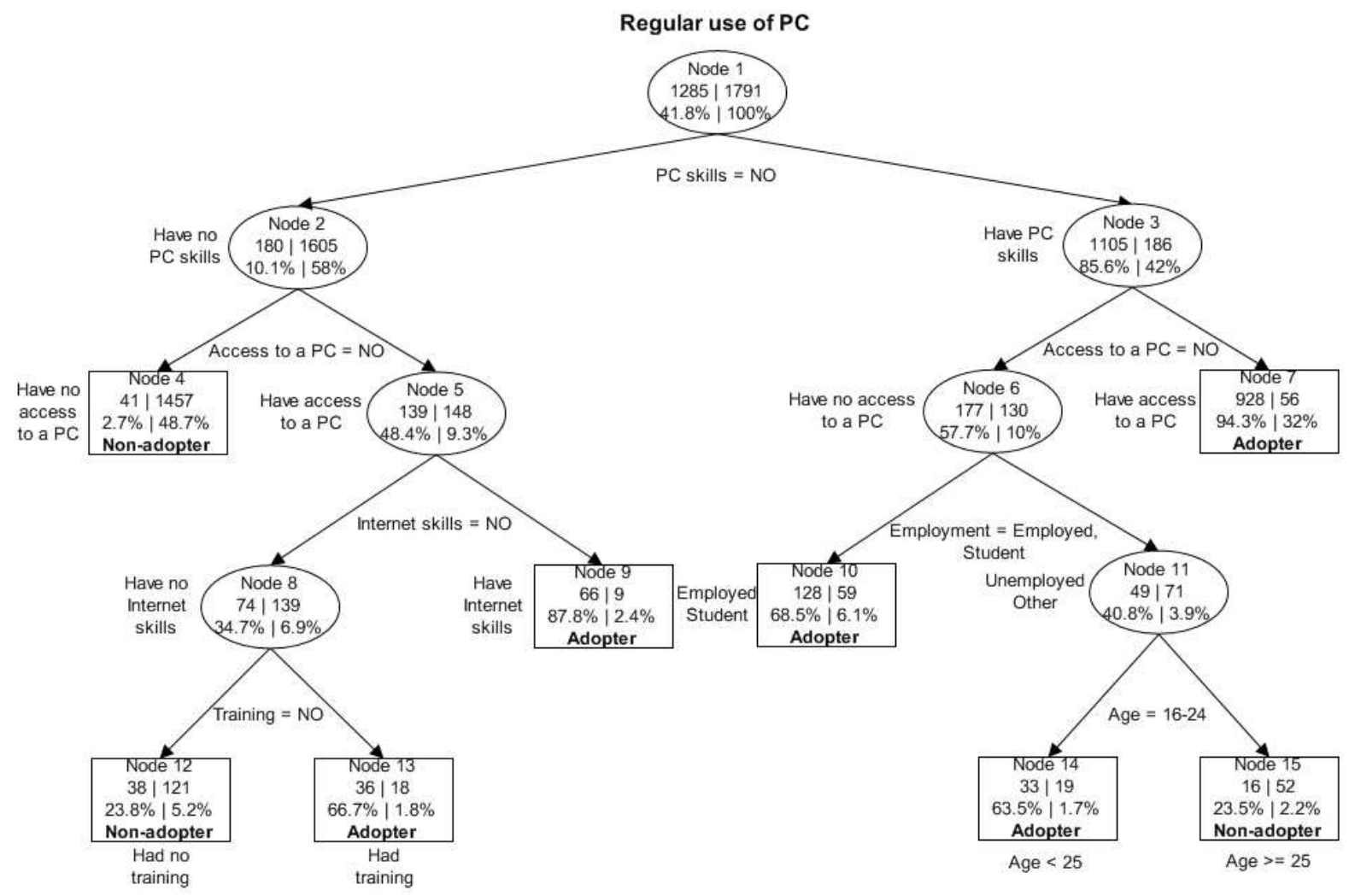

Figure 2: Classification tree for the regular use of PC

The overall percentage of correct classification for the regular use of a PC is $91.68 \%$. This percentage was achieved with 6 variables only. The estimated logistic regression for regular PC users gives $91.4 \%$ of correct classification (Table 4). However, 14 variables were included in the 
logistic regression (12 statistically significant), which suggests that the classification tree achieves slightly better correct classification result, with more a parsimonious model than the logistic regression.

The separation between those who use PC on a regular basis and those who don't is mainly, but by no means entirely, accounted for by a person's ability to use PC and to have access to a PC at home, i.e. can afford to purchase a PC. Our result suggests that investing in human capital by providing training in using $\mathrm{PC}$ and Internet for all age groups and making computer systems more affordable can mitigate the digital gap in PC use.

\section{Internet adopters}

Figure 3 shows the classification tree for regular access to the Internet. It shows that only four variables were used to construct the tree: (1) basic Internet skills, (2) access to the Internet, (3) employment and (4) age. The largest non-adopter group (i.e. not accessing Internet regularly) consists of 1913 (62.2\%) participants in the survey (Node 2). The largest adopter group (i.e. accessing the Internet regularly) contains 793 participants (25.8\% of all participants) (Node 5). They have basic Internet skills and access to the Internet at home. The next largest group, considered also as adopters, contains 271 , i.e. $8.8 \%$ of all participants, where $60.2 \%$ of them are adopters (Node 8). They have basic Internet skills, but don't have access to the Internet at home, they are either unemployed or classified as "others" and they belong to the age group 16-24. In other words they are probably accessing the Internet regularly either in a cyber café or in someone else's house.

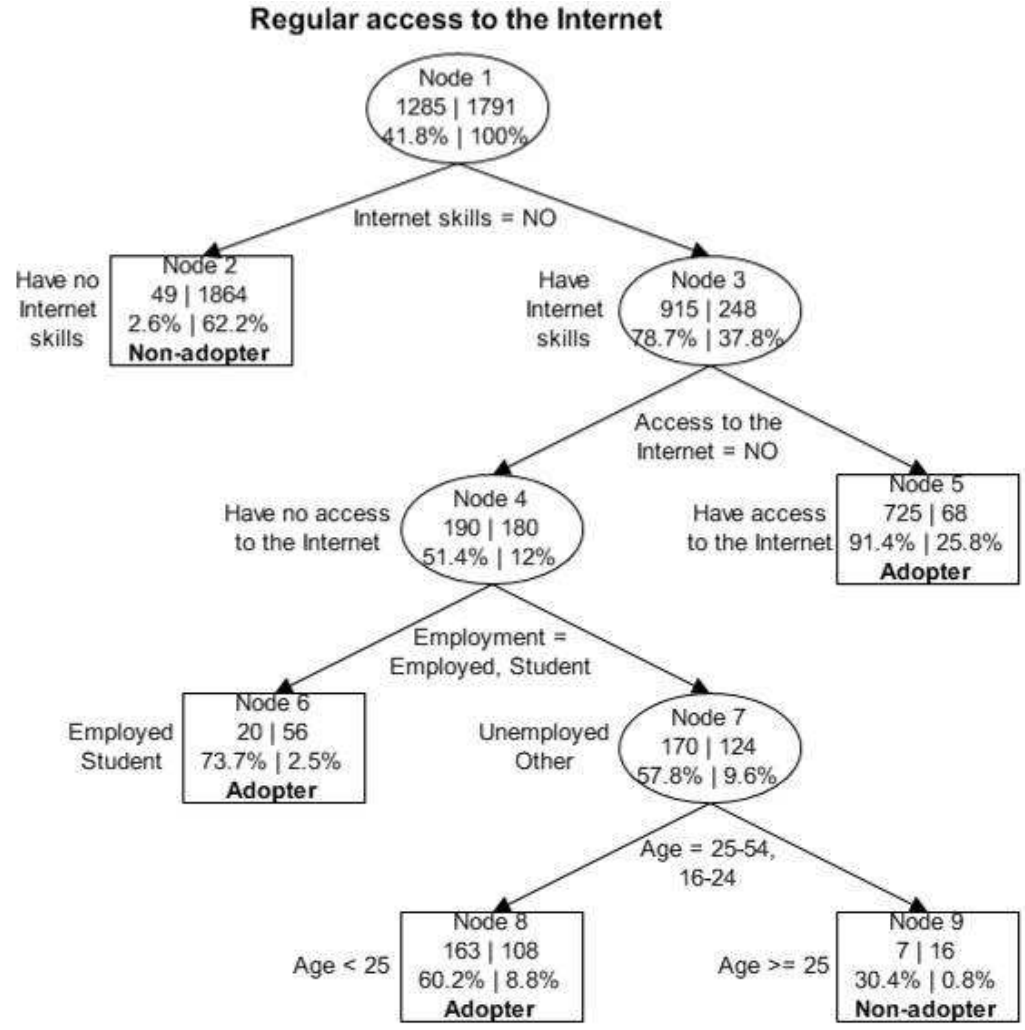

Figure 3: Classification tree for the regular access to the Internet

The overall percentage of correct classification for regular access to the Internet is $91.81 \%$. This percentage was achieved with four variables only. The estimated logistic regression for regular 
Internet users gives $91.9 \%$ of correct classification (Table 4) - slightly better results than in the case of the classification tree. However, 13 variables were included in the logistic regression (11 statistically significant), which suggests that the classification tree achieves better classification result, with more a parsimonious model than the logistic regression. The separation between those who access the Internet on a regular basis and those who don't is mostly determined by a person's basic Internet skills or lack of them, and by having access to the Internet at home i.e. whether the person could afford regular Internet subscription fee payments. Our results suggests that providing training in using Internet facilities for all age groups and making access to the Internet more affordable can bridge the digital gap in the Internet use.

\section{Mobile phone adopters}

Figure 4 shows the classification tree for mobile phone use. It shows that only four variables were used to construct the tree: (1) age, (2) income, (3) basic PC skills, (4) household size, (5) employment and (6) access to a PC. The largest non-adopter group (i.e. non-mobile phone users) consists of $550(17.9 \%)$ participants in the survey (Node 8). The largest adopter group (i.e. mobile phone users) contains 240 participants ( $7.8 \%$ of all participants) (Node 5). They are 55 or older with income over $€ 300$. The next largest group (non-adopters) contains 127 , i.e. $4.1 \%$ of all participants, where $64.6 \%$ of them are non-adopters (Node 12). The profile of the non-adopter in this group is the following: person is 55 or older, with income less than $€ 300$, with lack of basic PC skills, living in household with more than 2.5 persons, retired and without access to a PC at home.

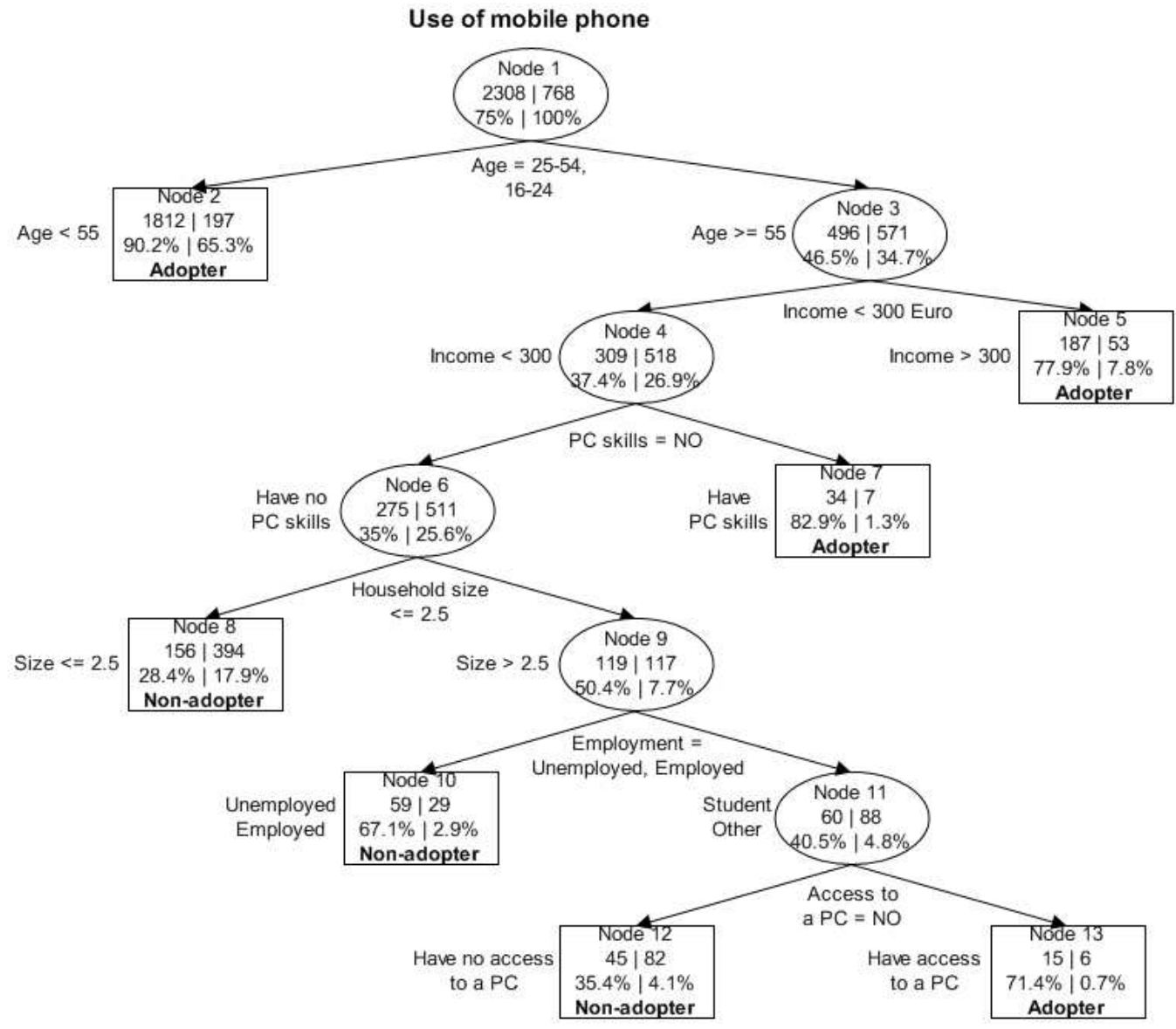

Figure 4: Classification tree for the use of mobile phone 
The overall percentage of correct classification for the mobile phone users is $83.97 \%$. This percentage was achieved with 6 variables only. The estimated logistic regression for mobile phone users gives $84 \%$ of correct classification (Table 4), almost the same result as with the classification tree. However, 13 variables were included in the logistic regression (12 statistically significant), which suggests that the classification tree achieves the same classification result, with more a parsimonious model than the logistic regression.

The separation between mobile phone users and non-users is mostly determined by a person's age and income. Our results suggests that providing the relevant information to the most senior citizens about the advantages that using mobile phone could have and lowering the mobile phone subscription fees can help in further adoption of the mobile phones.

\section{Logistic Regression}

In the logistic regression analysis 25 variables, i.e. potential predictors were considered, including interaction variables (between gender, age and income and year). A stepwise forward method for all three dependent variables was used, where only significant variables at the $5 \%$ level, according to the Wald test, were included. Table 4 gives estimated coefficients with their level of significance, odds ratios and a set of model diagnostics at the bottom. From all three models only in the model for regular access to the Internet the effect of time ("Year") variable was significant at the 5\% level. In other models there were no changes in the impact independent variables had on the dependent variables through time.

The $\operatorname{Exp}(B)$ column contains predicted changes in odds for a unit increase in the corresponding independent variable. Odds ratios less that 1 correspond to decreases in odds and odds ratios greater than 1 correspond to increases in odds. Odds ratios close to 1 indicate that unit changes in that independent variable do not affect the dependent variable. In an attempt to measure the strength of association in a logistic regression various $R^{2}-$ like measures were proposed. Among them the Cox and Snell's $R^{2}$ and Nagelkerke's $R^{2}$ are the most-reported. Because the Cox and Snell's $R^{2}$ can be less that 1.0 and difficult to interpret, Nagelkerke proposed further modification of the Cox and Snell's $R^{2}$ to assure that it can vary from 0 to 1 . The Hosmer-Lemeshow test of goodness of fit tests whether the model adequately fit the data. If the test is significant (the case of the PC user model at the 5\% level and mobile phone user model at the $1 \%$ level) then the model does not adequately fit the data. However, the Hosmer-Lemeshow statistics does not have good power for detecting particular types of lack of fit as noted by Agresti (2002).

\section{PC adopters}

From initial 25 potential predictors a stepwise forward method identified only 12 as statistically significant. The most significant and also large in magnitude were the coefficients for the following predictors: wealth (measured by access to a PC from home), then basic PC and Internet skills, young age group (16-24) and income. The income effect is monotonic, which means that the probability of being regular PC user increases with higher income. The odds of regular PC user are more than 13 times $(\operatorname{Exp}(B)=13.248)$ as large for those who have access to a PC at home as

for those who don't have access. The Nagelkerke's $R^{2}$ coefficient and the Cox and Snell's $R^{2}$ coefficient are 0.805 and 0.598 respectively. It means that $80.5 \%$ of variation in regular access to a PC is explained by the independent variables. To check for the overall predictive accuracy of the logistic regression models reported in Table 4, classification matrix has been constructed for each of them. However, only the overall percentages are presented in the last row. Overall correct classification for regular use of PC was $91.4 \%$. In other words the first model predicts over $91 \%$ of the observations correctly, classifying them correctly as PC adopter or non-adopter. 
As our results show, e-skills (basic PC and Internet skills) are on the top of the list of all predictors contributing the most to separation between adopters and non-adopters for all three technologies: PC, Internet and mobile phone. The technologically skilled person would be more likely to become an adopter of these technologies then others. Affordability of technology such as PC, Internet and mobile phone is the second major obstacle for adoption and regular use of computers and the Internet. Owing computer and having regular access to the Internet at home is still not affordable for most of potential users. The initial cost of purchasing the technology and ongoing subscription fees are still too high for most people keeping them on the other side of the digital divide.

Table 4: Regular use of PC, Internet and mobile phones (logistic regressions)

\begin{tabular}{|c|c|c|c|c|c|c|}
\hline \multirow{2}{*}{ Independent variable } & \multicolumn{2}{|c|}{ PC user } & \multicolumn{2}{|c|}{ Internet user } & \multicolumn{2}{|c|}{ Mobile user } \\
\hline & B & $\operatorname{Exp}(B)$ & B & $\operatorname{Exp}(B)$ & B & $\operatorname{Exp}(\mathrm{B})$ \\
\hline Constant & $-4.190^{\mathrm{a}}$ & 0.015 & $-4.273^{\mathrm{a}}$ & 0.014 & $-1.065^{\mathrm{a}}$ & 0.345 \\
\hline Year & & & $-0.664^{\mathrm{b}}$ & 0.515 & & \\
\hline Socio-demographics & & & & & & \\
\hline Gender & & & $0.360^{\mathrm{b}}$ & 1.433 & & \\
\hline $\begin{array}{l}\text { Gender } * \text { Year } \\
\text { Age }\end{array}$ & $\mathrm{a}$ & & & & & \\
\hline $16-24$ & $1.708^{\mathrm{a}}$ & 5.517 & & & $1.816^{\mathrm{a}}$ & 6.149 \\
\hline $25-54$ & $1.039^{\mathrm{a}}$ & 2.826 & & & $0.861^{\mathrm{a}}$ & 2.366 \\
\hline Age $*$ Year & & & & & & \\
\hline$(16-24) *$ Year & & & $1.427^{\mathrm{a}}$ & 4.166 & & \\
\hline$(25-54) *$ Year & & & $1.432^{\mathrm{a}}$ & 4.188 & & \\
\hline Education & b & & & & a & \\
\hline High school & $-0.359^{\mathrm{a}}$ & 0.699 & & & $0.546^{\mathrm{a}}$ & 1.726 \\
\hline Higher school & $0.020^{\mathrm{ns}}$ & 1.020 & & & $0.628^{\mathrm{a}}$ & 1.874 \\
\hline Employment & & & $\mathrm{a}$ & & & \\
\hline Employed & $0.486^{\mathrm{b}}$ & 1.626 & $0.314^{\mathrm{ns}}$ & 1.369 & $0.880^{\mathrm{a}}$ & 2.412 \\
\hline Unemployed & $-0.510^{\mathrm{b}}$ & 0.601 & $-0.575^{\mathrm{b}}$ & 0.563 & $0.487^{\mathrm{a}}$ & 1.628 \\
\hline Student & $0.045^{\mathrm{ns}}$ & 1.046 & $0.482^{\mathrm{ns}}$ & 1.619 & $0.694^{\mathrm{ns}}$ & 2.001 \\
\hline Children & & & & & $0.389^{\mathrm{a}}$ & 1.476 \\
\hline Household size & & & $-0.158^{\mathrm{a}}$ & 0.854 & & \\
\hline Income and wealth & & & & & & \\
\hline Income & $\mathrm{a}$ & & b & & a & \\
\hline Between 300 and 600 Euros & $0.418^{\mathrm{a}}$ & 1.518 & $0.379^{\mathrm{b}}$ & 1.461 & $0.812^{\mathrm{a}}$ & 2.253 \\
\hline Over 600 Euros & $0.658^{\mathrm{a}}$ & 1.931 & $0.526^{\mathrm{c}}$ & 1.692 & $1.554^{\mathrm{a}}$ & 4.728 \\
\hline Income * Year & & & & & & \\
\hline$(300-600$ Euros $) *$ Year & & & & & & \\
\hline (Over 600 Euros) * Year & & & & & & \\
\hline Access to a PC at home & $2.584^{\mathrm{a}}$ & 13.248 & & & $0.703^{\mathrm{a}}$ & 2.020 \\
\hline Access to the Internet from home & $0.389^{\mathrm{b}}$ & 1.475 & $2.749^{\mathrm{a}}$ & 15.620 & & \\
\hline e-skills & & & & & & \\
\hline Training on computer use & $0.643^{\mathrm{a}}$ & 1.902 & & & & \\
\hline Basic PC skills & $1.941^{\mathrm{a}}$ & 6.969 & $0.752^{\mathrm{a}}$ & 2.121 & $0.818^{\mathrm{a}}$ & 2.266 \\
\hline Basic Internet skills & $1.316^{\mathrm{a}}$ & 3.730 & $3.233^{\mathrm{a}}$ & 25.358 & $0.919^{\mathrm{a}}$ & 2.506 \\
\hline$-2 \log L$ & 1373.9 & & 1219.1 & & 2243.6 & \\
\hline Cox \& Snell $R^{2}$ & 0.598 & & 0.571 & & 0.326 & \\
\hline Nagelkerke $R^{2}$ & 0.805 & & 0.803 & & 0.483 & \\
\hline Hosmer \& Lemeshow test & $18.59^{\mathrm{b}}$ & & $12.43^{\mathrm{ns}}$ & & $36.52^{\mathrm{a}}$ & \\
\hline Overall \% of correct classification & $91.4 \%$ & & $91.9 \%$ & & $84 \%$ & \\
\hline
\end{tabular}

Note: ${ }^{\mathrm{a}}$ Denotes significance at the $1 \%$ level, ${ }^{\mathrm{b}}$ at $5 \%$ level, ${ }^{\mathrm{c}}$ at $10 \%$ level and ${ }^{\mathrm{ns}}$ at $>10 \%$ level. 
However, it should be made clear that lowering prices for these technologies, i.e. making them affordable should not be considered as the quick technological fix that will close the digital gap and make the late starters equally efficient as the early adopters. Contrary, it should be expected that the individuals already exposed to the new technologies are likely to benefit the most from the new technologies. Therefore, as our results show, the emphasis should be on education about the potential benefits that these technologies could bring to them and on development of their basic PC and Internet skills for beneficial use of the new technology.

\section{Internet adopters}

From initial 25 potential predictors a stepwise forward method identified only 11 as statistically significant (including interaction between predictors). The most significant among independent variables were the following: basic Internet skills, access to the Internet at home, time changing effect of 16-54 age group, basic PC skills, income and employment (students in particular). Again, the income effect is monotonic, which means that the probability of being regular Internet user increases with higher income. The odds of regular Internet user are more than 25 times $(\operatorname{Exp}(B)=25.358)$ as large for those who have basic Internet skills as for those who lack basic Internet skills. The Nagelkerke's $R^{2}$ coefficient and the Cox and Snell's $R^{2}$ coefficient are 0.803 and 0.571 respectively. It means that $80.3 \%$ of variation in regular access to the Internet is explained by the independent variables. Overall correct classification for regular use of the Internet was $91.9 \%$. In other words the second model in Table 4 predicts almost $92 \%$ of the observations correctly, classifying them correctly as Internet adopter or non-adopter.

\section{Mobile phone adopters}

From initial 25 potential predictors a stepwise forward method identified only 12 as statistically significant. The most significant among independent variables were the following: age (16-24 age group in particular), income (over $€ 600$ in particular), basic Internet and PC skills, employment (employed in particular). Similarly to PC and Internet use the income effect is monotonic in case of mobile phone users, which means that the probability of being mobile user increases with higher income. The odds of mobile phone user are more than 6 times $(\operatorname{Exp}(B)=6.149)$ as large

for those from 16-24 age group as for those who are older. The Nagelkerke's $R^{2}$ coefficient and the Cox and Snell's $R^{2}$ coefficient are 0.483 and 0.326 respectively, which are significantly lower than in the first two logistic regression models. It means that $48.3 \%$ of variation in mobile phone use is explained by the independent variables. Overall correct classification for mobile phone use was $84 \%$. In other words the last model in Table 4 predicts $84 \%$ of the observations correctly, classifying them correctly as mobile phone adopter or non-adopter.

\section{Comparing the Classification Tree and Logistic Regression Results}

There are a few advantages that classification tree approach has over the logistic regression when applying to the ICT adoption phenomenon.

First, the both classification trees and logistic regressions achieved almost the same predictive accuracy measured by the overall percentage of correct classification. However, in case of logistic regressions that was achieved at cost of including more than twice as many variables. This is a result of the way the classification tree is constructed. Namely, the classification tree is not using all statistically significant predictors as the logistic regression, but only those predictors who contribute to the best split at each stage. Second, while the logistic regression generally neglects interactions between covariates, assuming all covariates are independents, the classification tree takes interaction into account. If the interactions between covariates are significant, which is a 
reasonable assumption for most of the independent variables in the logistic regressions in Table 4, then the odds ratios are not quite appropriate measures of the impact independent variable could have on the dependent variables. Third, the logistic regression separates the sample into two groups: ICT adopters and non-adopters. However, the classification tree classify individuals from the sample into 8 (PC users), 5 (Internet users) and 7 (mobile phone users) groups providing additional information about adopters and non-adopters, i.e. detailed description of their profiles. Finally, the classification tree approach is simple to apply and its results are easy to interpret. By asking 4 (Internet users) or 6 (PC and mobile phone users) questions an individual can be classified as an adopter or non-adopter. There is no need to use odds ratios to calculate the scores and probability for each individual to see whether it should be classified as an adopter or non-adopter. Taking all these into consideration we would suggest use of the classification tree in the ICT adoption research for classifying and describing adopters and non-adopters.

Returning back to the three postulated hypotheses it could be said that hypothesis $\mathrm{H} 1$ was supported for the most socio-demographic characteristics and for at least one of the technologies considered. Based on the logistic regression results in Table 4 gender has a significant impact on regular Internet use only, i.e. regular PC use and use of mobile phone were not affected. PC and mobile phone adoption significantly decrease with age. In the case of mobile phone use both the classification tree and logistic regression identified age as the most significant factor. The age variable was used as the first variable to create the first split in the classification tree, while in the logistic regression for mobile phone use age group 16-24 has the highest odds. The only statistically significant interaction variable was detected in the cases of two age groups: 16-24 and 25-54 in the Internet use logistic regression model. In other words the digital gap between senior citizens (over 55) and the rest of the population increased significantly in 2007 for regular Internet use. Education was significant at the 5\% level of significance in the regular PC use logistic regression. However, unexpectedly the probability that the person with high school would be regular PC users decreases in comparison to the reference group, which is 'less than high school'. Education was not significant in the regular Internet use model, but was highly positively significant in the mobile phone use logistic regression with the probability which increases with the education level (an expected result). Having children in the household was a positive, significant factor only in the case of the mobile phone use logistic regression model.

Hypothesis $\mathrm{H} 2$ was supported at the 1\% (regular PC use and mobile use) and 5\% (regular Internet use) level of significance. The higher the monthly income the more likely a person will be classified as an ICT adopter. Owning a PC and having access to the Internet at home were used as a proxy variable for wealth. These two variables were identified as the most important in the regular PC use and regular Internet use logistic regression models as well as in the classification tree models.

Finally, hypothesis $\mathrm{H} 3$ was supported, i.e. there is a significant difference in PC, the Internet and mobile phone adoption based on differences of e-skills of the Serbian population. In case of regular PC use logistic regression model basic PC skills was the second most important factor (after access to a PC at home). In the regular Internet use logistic regression model the most important factor was basic Internet skills and then access to the Internet at home. A similar result was obtained with the classification tree, i.e. the same two variables were used to split the tree starting from the top, i.e. from Node 1; see Figure 2 for regular PC use and Figure 3 for regular Internet use. The training variable was significant only in the regular PC use logistic regression model.

Since ICT adoption in Serbia is mostly determined by the factors from the 'income and wealth' and 'e-skills' blocks in the conceptual model (Figure 1), we can conclude that the Serbian population is characterized with a mixture of the first-level, i.e. basic digital divide which describes access to ICT or lack of it and the second-level digital divide which describes autonomy of use and skills or lack of them. 


\section{Concluding Remarks}

This study is designed to examine the main factors that impact ICT adoption and the digital divide in Serbia. Based on results from logistic regression models and classification trees presented in Tables 3 to 4 and Figures 2 to 4 it was found a digital divide exists at both first-level and second-level digital divide. In other words there is evidence of the differences in access and also in e-skills in the Serbian population. A representative of the most digitally deprived segments of the Serbian population could be described as a person over 55, with a low monthly income (less than 300 Euros), who has no access to a PC and the Internet at home and has no basic PC and Internet skills.

There were no significant changes in the digital divide between 2006 and 2007. A small but statistically significant change has been detected in the case of regular Internet use where the gap has increased with age.

Both logistic regression and the classification tree identified the main determinants of the digital divide in Serbian society, which are 'income and wealth' and 'e-skills', as we labeled them in the conceptual model in Figure 1. In the case of mobile phone use age was the most important determinant which separates adopter from non-adopter. More specifically, owning a computer and accessing it and the Internet from home have the highest odds in the logistic regression models which means there is a higher probability for a person who has access to a PC and the Internet at home to be classified as an adopter. Next to the access factor is a group of factors labeled as ' $\mathrm{e}$ skills': basic PC and Internet skills, both with quite high odds in the logistic regression models. This means the probability that someone will be classified as an adopter increases a couple of times if the person has basic PC and Internet skills. The same result was obtained by using the classification tree method. Namely, the same two variables were used to split the tree from the top, i.e. from Node 1 in the case of regular PC and Internet use classification trees.

The same level of classification accuracy has been achieved with both logistic regression and classification tree. In the case of regular PC use the percentages of a correct classification were 91.4 and $91.68 \%$, respectively; in the case of regular Internet use $91.9 \%$ and $91.81 \%$, respectively and finally in the case of mobile phone use $84 \%$ and $83.97 \%$, respectively. However, these results in all three cases were achieved with a more parsimonious model when the classification tree was used. Namely, about half as many variables were included in the classification tree model than in the logistic regression model. Therefore the classification tree model is recommended to be used for the classification of an individual as an ICT adopter or non-adopter.

There are certain economic and socio-political reasons why public policy should take an active approach toward closing the digital divide in Serbian society. In the last two decades two significant trends were observed in the economy. First, the information-related industries and services are becoming the main contributors to the national income, replacing manufacturing industries in that position. Second, e-commerce, in particular business-to-business e-commerce, is making an increasing contribution to the national income. Those who have not adopted an active approach toward these global changes risk being left behind in the international market. From a sociopolitical perspective we treat information as a public good. If it is a public good, then society should have increased access to it. Making access to ICTs affordable to everyone would increase the participation of disadvantaged population (low income, less educated, and senior citizens) in public and policy matters. That would also help in creating social networks of citizens with common interests even in the case of physical distance between them.

Our results have some interesting implication for digital divide researchers and policy-makers.

Serbia has a range of challenges to face, among other poor purchasing power of households, infrastructure deficiencies and inadequate literacy (computer literacy in particular) of the popula- 
tion. Both logistic regression and the classification tree, clearly show that the access to ICT (firstlevel digital divide) is still the key factor in the digital divide in Serbia. In other words, access to a PC and the Internet from home contributes significantly to the separation of adopters and nonadopters. Finding ways to increase the home access of low-income families to the Internet should remain a policy priority. The issue of the digital divide suggests also disparity in terms of age, education, income, and employment between the adopters and non-adopters. This highlights the need for affordability and accessibility of emerging ICTs for citizens with lower education, income and occupation level and also to elderly people.

We believe that national government policy plays a key role in creating a legal framework and creative economic and social environment that will encourage further investment in ICT infrastructure and use as well as a wider public education about the benefits of technology and its use. It would be difficult if not impossible to bridge the gap without an overall, consistent governmental policy that would encourage and support digital equity. However, as Ferro, Cantamessa \& Paolucci (2005) emphasized, the choice of which gap to bridge may actually be strategically important in order to maximize the impact of the investment on the entire system.

Bridging the digital gap could be achieved by reduction of tariffs and taxes on ICT products and services and with the further deregulation of telecommunication services. Alternatively or simultaneously this could be provided in the form of public access points (public libraries, city halls, public schools, etc.) where technical support could be provided. These public access points should either be free of charge or a minimal fee could be imposed. These public access points will increase awareness of excluded citizens about new services and how they can benefit from them. At the same time these citizens could gain confidence when using ICTs and improve their computer and Internet skills. Our results also suggest that investing in human capital by providing training which will build the basic PC and Internet skills for all age groups can mitigate the digital gap in PC and Internet use.

This study is limited in three main ways that future research can perhaps address. First, our reliance on a survey with a predefined questionnaire imposes constraints on the depth and focus of the analysis. Second, we used survey data for two consecutive years and addressed partially changes in the digital gap. However, data on the micro level over a longer time period may provide the opportunity to explore the speed and direction of changes in the digital divide. Third, from a methodological point of view an alternative to classification tree should be considered. The percentage of correct classification is quite high particularly for computer and Internet use in both logistic regressions and classification trees. However, quite often the classification accuracy is not so high when the model is applied to observations outside the sample. This phenomenon is known as over-fitting. More robust modifications of the classification tree should be tried to improve model prediction accuracy and model stability.

\section{Acknowledgement}

We would like to thank John Green, Senior Lecturer in the School of Information and Social Sciences at the Open Polytechnic of New Zealand for valuable comments on the first draft of this paper. However, the authors should be held responsible for any remaining errors.

\section{References}

Agresti, A. (2002). Categorical data analysis (2nd ed.). New York: John Wiley and Sons.

Angela, M., \& Sicat, M. (2004). Statistics on women and men and ICT: The ECE region. Paper presented at the Regional Symposium on Mainstreaming Gender into Economic Policies, Geneve, January 28-30. 
Baćević, L. (2003). The development of Internet in Yugoslavia. In O. Spassov \& C. Todorov (Eds.), New media in Southeast Europe. SOEMZ, European University Viadrina (Frankfurt - Oder) and Sofia University St. Kliment Ohridski.

Baliamoune-Lutz, M. (2003). An analysis of the determinants and effects of ICT diffusion in developing countries. Information Technology for Development, 10(3), 151-169.

Barzilai-Nahon, K. (2006). Gaps and bits: Conceptualizing measurements for digital divide/s. The Information Society, 22, 269-278.

Bauer, J. M., Berne, M., \& Maitland, C. F. (2002). Internet access in the European Union and in the United States. Telematics \& Informatics, 19(2), 117-137.

Beilock, R., \& Dimitrova, D. V. (2003). An exploratory model of inter-country Internet diffusion. Telecommunications Policy, 27, 237-252.

Bughin, J. (2001). E-push or e-pull? Laggards and first-movers in European on-line banking. Journal of Computer-Mediated Communication, 7(1).

Chinn, M. D., \& Fairlie, R. W. (2004). The determinants of the global digital divide: A cross-country analysis of computer and Internet penetration. Economic Growth Center Discussion Paper no. 881. Yale University.

Choudrie, J., \& Dwivedi, Y. K. (2006). Examining the socio-economic determinants of broadband adopters and non-adopters in the United Kingdom. In the Proceedings of the $39^{\text {th }}$ Hawaii International Conference on System Sciences, Kauai, HI, USA, January 4-7.

Crenshaw, E. M., \& Robison, K. K. (2006). Jump-starting the Internet revolution: How structural conduciveness and global connections help diffuse the Internet. Journal of the Association for Information Systems, 7(1), 4-18.

Cuervo, M. R. V., \& Menéndez, A. J. L. (2006). A multivariate framework for the analysis of the digital divide: Evidence for the European Union-15. Information \& Management, 43, 756-766.

Curry, J., \& Kenney, M. (2006). Digital divide or digital development? The Internet in Mexico. First Monday, 11(6).

Dewan, S., \& Riggins, F. (2005). The digital divide: Current and future research directions. Journal of the Association for Information Systems, 6(12), 298-337.

Dewan, S., Ganley, D., \& Kraemer, K. L. (2005). Across the digital divide: A cross-country multitechnology analysis of the determinants of IT penetration. Journal of the Association of Information Systems, 6(12), 409-432.

DiMaggio, P., \& Hargittai, E. (2001). From the 'digital divide' to 'digital inequality': Studying Internet use as penetration increases. Princeton University.

Dimitrova, D. V. (2002). Internet adoption in the post-communist countries. Medien Journal, 26(3), 64-71.

Dinlersoz, E. M., \& Hernández-Murillo, R. (2004). The diffusion of electronic business in the U.S. Working Papers Series 2004-009B. The Federal Reserve Bank of St. Louis.

Eamon, M. K. (2004). Digital divide in computer access and use between poor and non-poor youth. Journal of Sociology \& Social Welfare, 31(2), 91-112.

Ferro, E., Cantamessa, M., \& Paolucci, E. (2005). Urban versus regional divide: Comparing and classifying digital divide. In M. Bohlen, J. Gamper, W. Polasek, \& M. A. Wimmer (Eds.), E-government: Towards electronic democracy (Vol. 3416, pp. 81-90). Berlin: Springer Verlag.

Forman, C., Goldfarb, A., \& Greenstein, S. (2005). How do industry features influence the role of location on Internet adoption? Journal of the Association of Information Systems, 6(12), 383-408.

Gatnar, E. (2002). Tree-based models in statistics: Three decades of research. In K. Jajuga, A. Sokolowski, $\&$ H-H. Bock (Eds.), Classification, clustering and data analysis: Recent advances and applications (pp. 399-408). Berlin: Springer Verlag. 
Guillén, M. F., \& Suárez, S. L. (2005). Explaining the global digital divide: Economic, political and sociological drivers of cross-national Internet use. Social Forces, 84(2), 681-708.

Hargittai, E. (1999). Weaving the Western web: Explaining differences in Internet connectivity among OECD countries. Telecommunications Policy, 23, 701-718.

Hargittai, E. (2002). Second-level digital divide: Differences in people's online skills. First Monday, 7(4). Retrieved August 3, 2007 from http://www.uic.edu/htbin/cgiwrap/bin/ojs/index.php/fm/article/view/942/864

Harrington, J. (2003). The digital divide: Lessons from the People's Republic of China. Troy State University.

Henderson, J., Dooley, F., \& Akridge, J. (2000, July 30). Adoption of e-commerce strategies for agribusiness firms. Paper presented at the American Agricultural Economics Association Annual Meeting, Tampa, FL.

Hoffman, D. L., \& Novak, T. P. (1998). Bridging the racial divide on the internet. Science, 280, $390-391$.

Horvitz, R. (2002). Serbia - A preparatory ICT assessment. Global Internet Policy Initiative.

Kauffman, R. J., \& Techatassanasoontorn, A. A. (2005). Is there a global digital divide for digital wireless phone technologies? Journal of the Association for Information Systems, 6(12), 338-382.

Kennedy, T., Wellman, B., \& Klement, K. (2003). Gendering the digital divide. IT \& Society, 1(5), 72-96.

Kiiski, S., \& Pohjola, M. (2002). Cross-country diffusion of the Internet. Information Economics \& Policy, 14(2), 297-310.

Knežević, B. R., \& Vidas-Bubanja, M. (2006). Analysis of electronic commerce adoption in Serbia. Unpublished manuscript. Retrieved August 3, 2007 from http://ssrn.com/abstract=941390

Köllinger, P., \& Schade, C. (2003). Analyzing e-learning adoption via recursive partitioning. Discussion Papers 346, German Institute for economic Research.

Kostov, Z. (2006). Global tendencies and local implications: Cyber exclusion of and within Western Balkan countries'. The Centre for the Study of Global Governance Working Paper 40. London School of Economics and Political Science.

McLaren, J., \& Zappalà, G. (2002). The 'digital divide' among financially disadvantaged families in Australia. First Monday, 11(7). Retrieved August 3, 2007 from http://www.firstmonday.org/ISSUES/issue7_11/mclaren/index.html

Milner, H. V. (2006). The digital divide. Comparative Political Studies, 39(2), 176-199.

Norris, P. (2001). Digital divide: Civic engagement, information poverty, and the internet worldwide. Cambridge; New York: Cambridge University Press.

Novak, T. P., Hoffman, D. L., \& Venkatesh, A. (1998). Diversity on the internet: The relationship of race to access and usage. In A. Garmer (Ed.), Investing in diversity: Advancing opportunities for minorities and the media. Washington, D.C.: The Aspen Institute.

Oyelaran-Oyeyinka, B., \& Lal, K. (2005). Internet diffusion in sub-Saharan Africa: A cross-country analysis. Telecommunications Policy, 29(7), 507-527.

Pew Internet Project Report (2004, March 25). Older Americans and the Internet. Retrieved August 3, 2007 from http://www.pewinternet.org/PPF/r/117/report_display.asp

Pew Internet Project Report (2005, December 28). Women and men online. Retrieved August 3, 2007 from http://www.pewinternet.org/PPF/r/171/report_display.asp

Pew Internet Project Report (2006, January 22). Generations online. Retrieved August 3, 2007 from http://www.pewinternet.org/PPF/r/170/report_display.asp 
Stojković, B. (2003). Development of the Internet: Social, political and cultural effects on the Serbian society. In O. Spassov \& C. Todorov (Eds.), New media in Southeast Europe: SOEMZ, European University Viadrina (Frankfurt - Oder) and Sofia University St. Kliment Ohridski.

Tengku, M. F. (2005). Digital divide in Malaysia: Examining the issues of income, workplace and geographical differences in diffusing ICT to the mass public. $\mathrm{PhD}$ dissertation, Waseda University, Tokio.

Tukiainen, J. (2004). Access to computer, Internet and mobile phone at home in Finland, Ireland, Netherlands and Sweden. Vatt Discussion Papers 324, Government Institute for Economic Research.

United Nations. (2005). UN global e-government readiness report 2005: From e-government to einclusion. The Department of Economic and Social Affairs of the United Nations.

van Everdingen, Y. M., \& Waarts, E. (2003). The effect of national culture on the adoption of innovations. Marketing Letters, 14(3), 217-232.

Vehovar, V., Sicherl, P., Hüsing, T., \& Dolničar, V. (2006). Methodological challenges of digital divide measurement. The Information Society, 22, 279-290.

Waarts, E., \& van Everdingen, Y. M. (2005). The influence of national culture on the adoption status of innovations: An empirical study of firms across Europe. European Management Journal, 23(6), 601610.

Warschauer, M. (2002). Reconceptualizing the digital divide. First Monday, 7(7). Retrieved August 3, 2007 from http://www.uic.edu/htbin/cgiwrap/bin/ojs/index.php/fm/article/view/967/888

Wong, P.-K. (2002). ICT production and diffusion in Asia: Digital dividends or digital divide? Information Economics and Policy, 14(2), 167-187.

\section{Biographies}

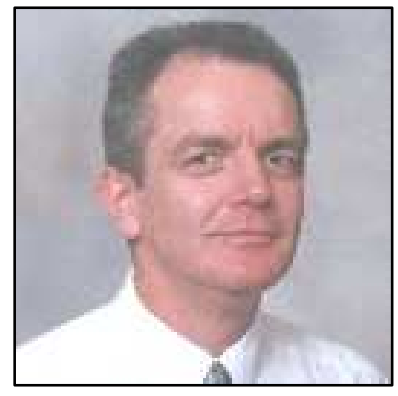

Dr Zlatko J Kovačić is an Associate Professor in the School of Information and Social Sciences at the Open Polytechnic of New Zealand. Zlatko has a varied academic background and research interests, ranging from core interests relating to IT careers, learning and teaching, to eCommerce, eLearning, time series analysis, multivariate analysis and Web (data) mining. His current research is focused on social and cultural aspects of information technology, on cognitive processes in distance education using computers and communications technologies and time series analysis of emerging financial markets.

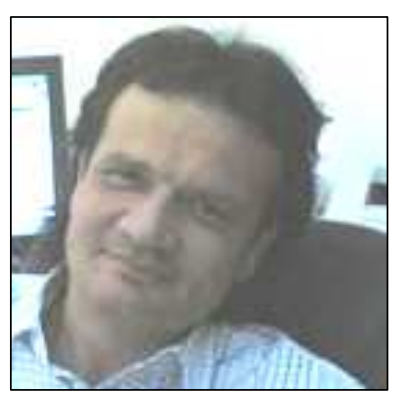

Dr Dragan Vukmirović is an Associate Professor in the Faculty of Organizational Sciences at the Belgrade University and Director of the Statistical Office of the Republic of Serbia. Dragan published papers and participated in research projects in the areas of statistics, ebusiness and marketing. He was founder and coordinator of the master studies in e-business and the postgraduate studies on the Internet technology and e-business at the Faculty of Organizational Sciences. 